\title{
The Influence of Social Networking on Lifestyle: A Higher Education Perspective
}

\author{
${ }^{*}$ D Veerasamy, J. P. Govender \\ Durban University of Technology, South Africa \\ *veerasamyd@dut.ac.za
}

\begin{abstract}
Social networks have become a way of life for many people who use them to connect and communicate with the world at large. Social media is defined as any tool or service that uses the Internet to facilitate conversations. Facebook is one of the most popular social networking sites (SNSs) and has a total of 55 million active users worldwide with an average of 250000 new registrations per day. After Yahoo, MySpace and Google, Facebook is also the fourth most popular SNS in South Africa. The purpose of the paper was to determine whether social networks have an influence on higher education students' lifestyles and behaviour. This research was descriptive and quantitative in nature. The sample comprised 386 students studying at the Durban University of Technology (DUT). The results indicated that the majority of the respondents preferred Facebook as their social network of choice. More than half of the respondents indicated that they access their preferred social network five times or more per day. The majority of the respondents agreed that social networks allow for global interaction and that maintaining relationships has become easier with social networking,
\end{abstract}

Keywords: Social networks, social media, social networking sites

\section{Introduction}

Marketing tools have changed and advanced over the years as new technologies have made it possible to reach the market in new innovative ways. Social media has created more opportunities to connect and network with friends, family, and customers. This means that marketing has new tools as well. The technology of social media that has emerged has created new tools and opportunities for marketing. These new tools require new skills as well as different approaches. They have not changed the basic question of when and how to use it to be effective, efficient, and successful. Companies also need to be able to determine which of the different social media the company should or should not use in marketing their products, services, and/or company. This is similar to companies deciding whether to use print ads, billboards, celebrity endorsements, television or radio commercials, coupons, etc. These new tools have created opportunities that require new knowledge and proficiencies for marketers (Schmidt and Ralph, 2011). DuPlessis, Van Heerden and Cook (2010) maintain that social networking sites (SNSs) are a new phenomenon, which has gained significant uptake over the past few years. SNSs are new and trendy marketing and branding tools that offer good advertising and marketing opportunities. Social networks have become a way of life for many people who use them to connect and communicate with the world at large. The increase in access to the internet and social networking sites has been a blessing for marketers in that they are now able to access a wider customer base by communicating with these young people and getting timely, accurate information about their needs, wants, likes, dislikes expectations and views on various issues, ideas, products and services.

Social media have changed the way that marketers can communicate with their brands - from mass messages to intimate conversations. As marketing moves into social media, marketers must remember that for most people, social media are meant to be a social experience, not a marketing experience. Social media is defined as any tool or service that uses the Internet to facilitate conversations (Lamb, Hair and McDaniel, 2013). According to Giannini (2010), the way people communicate has changed drastically over the last decade, and marketing professionals are working hard to try and keep up with these trends. Social media are often defined narrowly and considered to be synonymous with social networks like Facebook and MySpace. While these popular cyber destinations are types of social media, there are other non-network types as well where participants can produce, control, publish, critique, rank and interact with content online. Given the situation, the aim of this paper is to determine whether social networks influence higher education students' lifestyles and behaviour. The objectives of this paper are to determine if social networks affect the lifestyles and behaviour of higher education students and to analyse the extent to which these social networks affect the lifestyles and behaviour of higher education students. 


\section{Literature Review}

Social networking sites are different from other communication mediums in that they allow users to communicate with each other and to locate like-minded individuals. Once they find each other, they can form communities based on their mutual interests. Thus, social networking sites help shift power from the organisation to the consumer. As social networking sites continue to grow in popularity, firms can no longer solely rely on traditional mediums to create and maintain public perception of their product. Organisations now have an opportunity to maintain a persistent connection with their consumers. These social networking sites can help to identify their most influential consumers, encourage participation in product development, and improve brand sentiment. Social networks can be used to raise awareness; connect events with attendees; inspire and educate; share insight and provide support; share tricks of the trade and create community for customers. Therefore, social media presents an exclusive opportunity for marketers to find and communicate with consumers in ways that are faster and more personal than ever before. Lamb, Hair and McDaniel (2013) discuss how SNSs allow individuals to connect or network with friends, peers and business associates. Connections may be made around shared interests, shared environments or personal relationships. Depending on the site, connected individuals may be able to send each other messages, track each other's activity, see each other's personal information and share multimedia.

There are six categories of social media users: Creators - those who produce and share online content like blogs, videos, websites and articles; Critics - those who post comments, ratings and reviews of products and services on blogs and forums; Collectors - those who collect information and vote for websites online; Joiners - those who maintain a social networking profile and visit other sites; Spectators - those who read blogs, listen to podcasts and watch videos and Inactives - those who do none of these things. Strauss and Frost (2012) state that where customers go, organisations follow. Because today's customer researches brands online and learns about products from other customers in social media, businesses want to join in and influence the conversations - or start them when launching a new product. According to Shimp (2010), social networking sites such as MySpace and Facebook have signed up millions of people around the globe who interact with friends, share opinions and information and create online communities of people who have similar interests and wish to share their experiences with others. Therefore, marketers have tapped into these celebrated social networking sites or have created their own social networks as a mechanism for communicating with consumers about their offerings. Facebook is one of the most popular SNSs and has a total of 55 million active users worldwide with an average of 250000 new registrations per day. After Yahoo, MySpace and Google, Facebook is also the fourth most popular SNS in South Africa; our country contributes 603960 Facebook users to the global number of users. The majority of South African Facebook users are female (63\%) with males at 37\% (du Plessis, van Heerden and Cook 2010).

Albarran (2013) explains that Facebook is the largest social media site in the world, with over 500 million global users and counting. Facebook debuted in 2004; the site was originally open only to college students. Within two years, Facebook opened its site to all 'followers' within their network. MySpace was the first social media site to gain widespread recognition, it debuted in 2002. MySpace was the original big player in the social media market; however, it has not been able to keep up with the rapid growth of sites like Facebook and Twitter. These two sites have been adopted by most businesses and industries that have moved into social media. Facebook is by far the largest SNS, and is popular with both individuals and groups. How an individual uses Facebook differs from the way a group or company uses Facebook. While individual Facebook users create profiles, organisations operate as pages. Facebook has proved to be fertile ground for new marketing ideas and campaigns (Lamb, Hair and McDaniel 2013). The social media study conducted by Cone Inc. in 2008 showed that $93 \%$ of social media users believe that companies they buy from should have a presence in social media. In addition, $85 \%$ believe that a company should not only be present but should also interact with its consumers via social media (Giannini 2010).

\section{Methodology}

The purpose of this paper was to determine whether social networks have an impact on higher education students' lifestyles and behaviour. This research is cross-sectional, descriptive and quantitative in nature. 
Sample: The sample comprised 379 students studying at the Durban University of Technology (DUT). The DUT has a student population enrolment number of 23000 . The sample size was guided by Sekaran (2003), who suggests that population sizes of 20000 and 30000 warrant sample sizes of 377 and 379 respectively. Convenience sampling which is the cheapest and easiest way to conduct research, was used to select respondents

Instrument and procedure: The data was gathered by administering a questionnaire to students at the DUT.

Data analysis: The collected data was analyzed by using the Statistical Package for Social Sciences (SPSS) version 14.0 for Windows. A descriptive analysis of the biographical data (age, gender, student category) was done. The reliability of the scale was measured using Cronbach alpha.

\section{Findings}

Table 1: Biographical details of respondents

\begin{tabular}{ll}
\hline Biographical Characteristics & Percentage $(\%) \mathbf{n = 3 7 9}$ \\
\hline Gender: & \\
Male & 45 \\
Female & 55 \\
Age: & \\
$18-20$ & 30 \\
$21-23$ & 25 \\
$24-26$ & 15 \\
27 and older & 30 \\
Student category: & \\
Full time & 80 \\
Part time & 20 \\
\hline
\end{tabular}

It emerged that $45 \%$ of the respondents were male while $55 \%$ were female. $30 \%$ of respondents were in the age category $18-20,25 \%$ were $21-23,15 \%$ were $24-26$ and $30 \%$ were 27 years or old. $80 \%$ of the respondents were full time students while $20 \%$ were registered part time. The results are presented in Table 1.

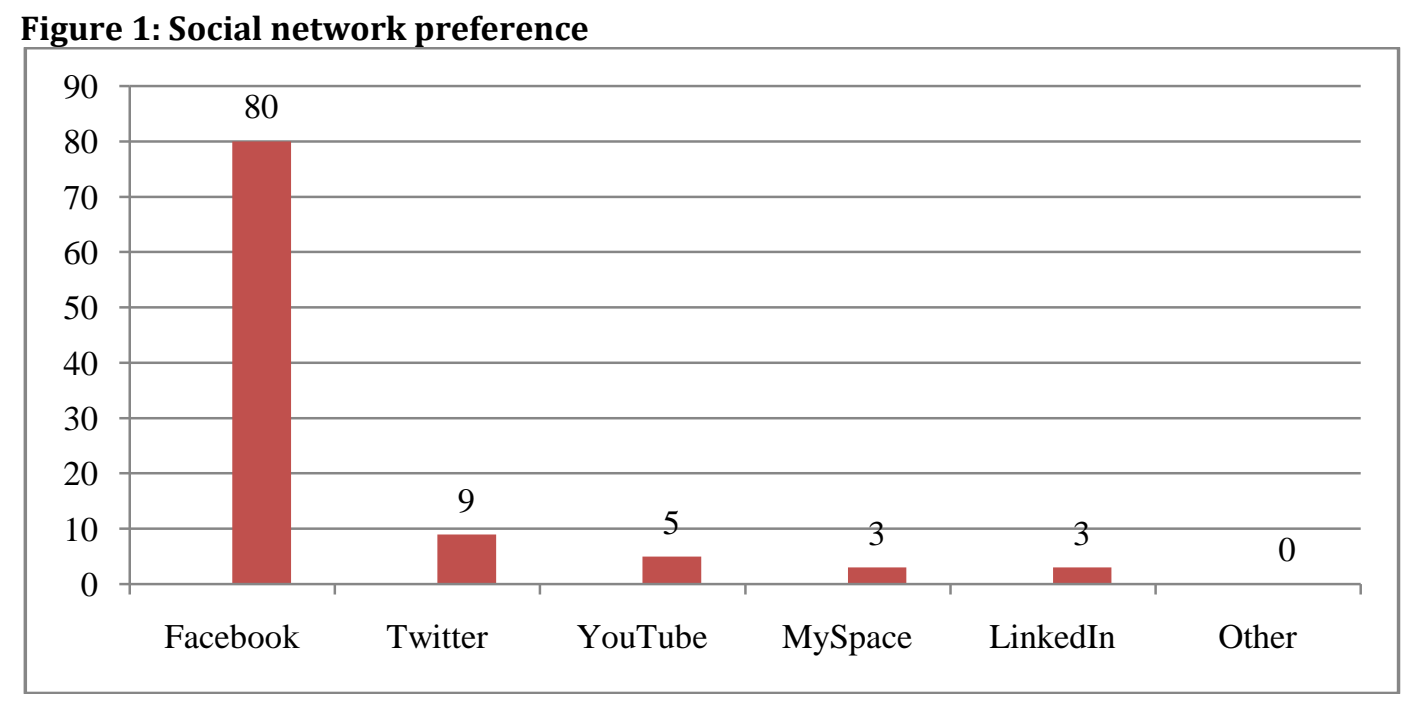

As depicted in Figure 1,80\% of the respondents preferred Facebook as their social network of choice, 9\% indicated Twitter, 5\% YouTube and 3\% for both MySpace and LinkedIn. In a study of 10000 visitors to the top 40 internet retailers in 2009, the following were noted as the most popular social media sites: Facebook 81\%, YouTube 31\%, My Space 22\%, Twitter 16\%, LinkedIn $12 \%$, Flickr 7\%, Other social sites $2 \%$ and Yelp 2\% (Strauss and Frost, 2012). Consistent with numerous media reports, the top two sites in the Ofcom (2008) quantitative and qualitative research were Facebook and MySpace. The majority of 
adults who had used a social networking site had a profile on Facebook (62\%) and this was the most mentioned main social networking site (49\%).

Figure 2: Frequency of daily access of social networks

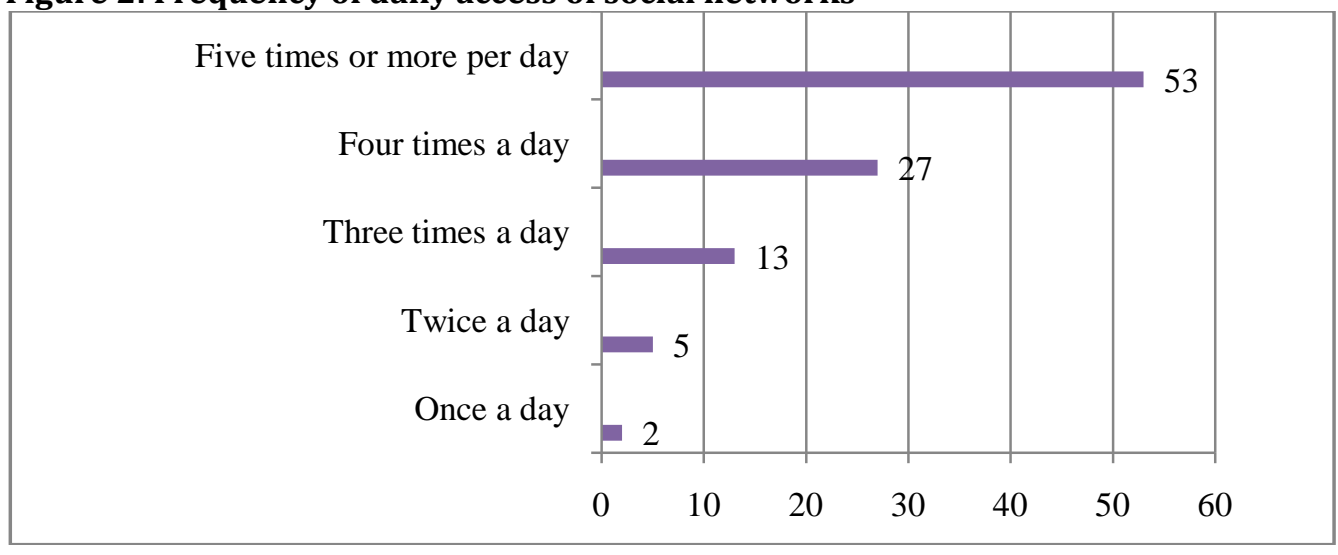

More than half of the respondents (53\%) indicated that they access their preferred social network five times or more per day. $27 \%$ accessed it four times a day, $13 \%$ accessed three times a day $5 \%$ twice a day whilst only 2\% accessed once a day as shown in Figure 2. According to the Ofcom (2008) report, half of all users accessed social networking sites at least every other day. Respondents with a profile on a social networking site claimed to use the sites fairly frequently, with $87 \%$ accessing their profile at least once a week, and $50 \%$ at least every other day. Some adults in their early twenties reported feeling 'addicted' to social networking sites and were aware that their usage was squeezing their study time. Some users described how they might plan to go onto their site to check for messages and then emerge a few hours later - having been drawn into commenting, searching and generally having fun.

\section{Figure 3: Average cost of social networking per month}

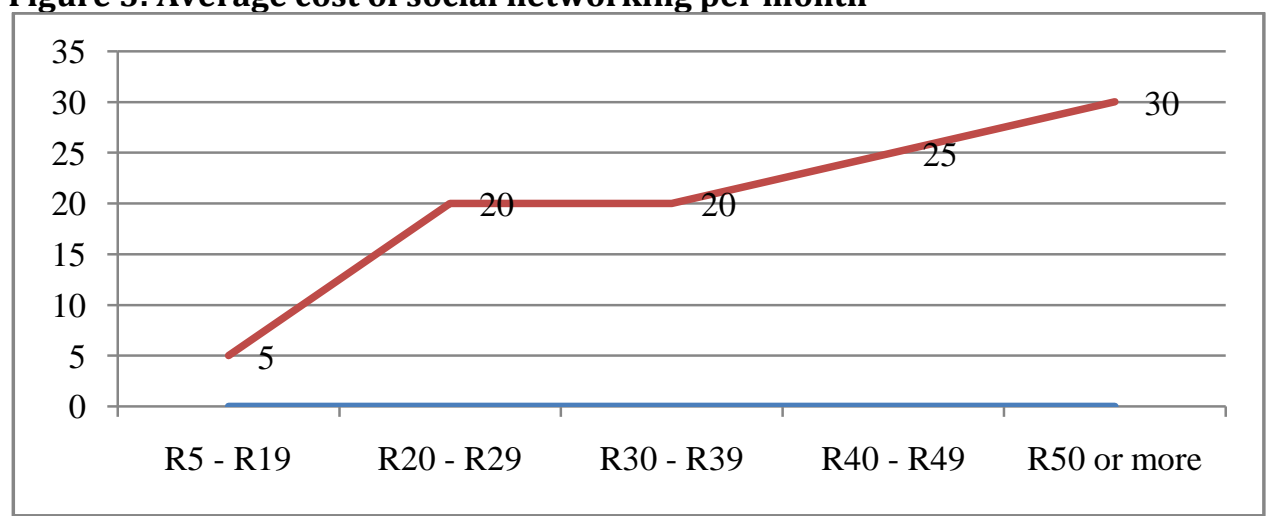

Figure 3 indicates that $30 \%$ of the respondents spent R50 or more per month on social networking. $45 \%$ spent between R30 - R49 per month, 20\% spent R20-R29 and 5\% spent R5-R19 per month.

\section{Figure 4: Social networking being only for young people}

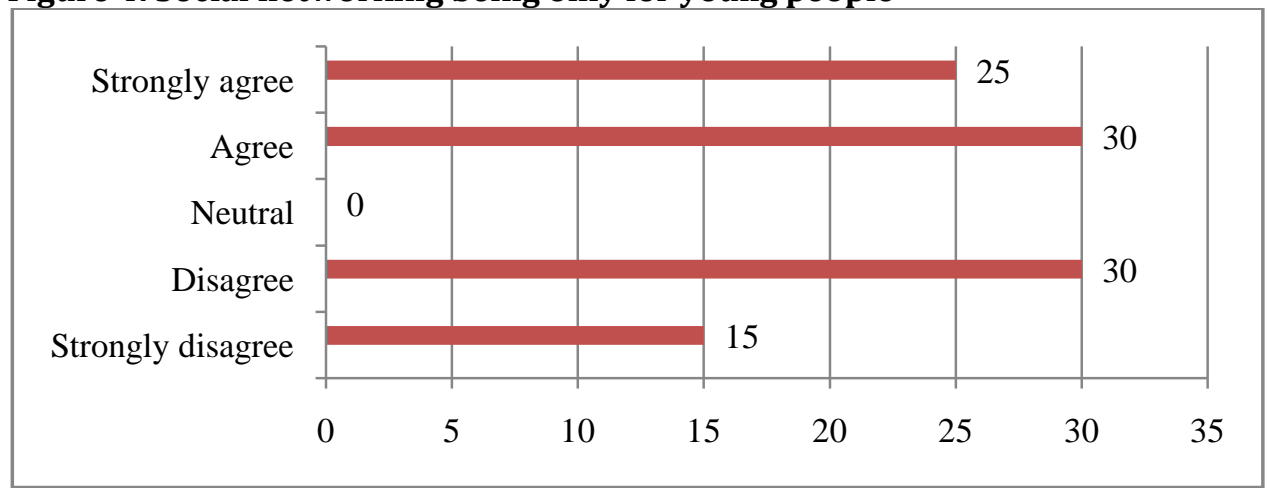


When asked whether social networking is only for young people, the results were as follows: $25 \%$ strongly agreed, $30 \%$ agreed, $30 \%$ disagreed, and $15 \%$ strongly disagreed while no respondents were neutral, as shown in Figure 4. Ofcom (2008) research shows that just over one fifth (22\%) of adult internet users aged $16+$ and almost half (49\%) of children aged 8-17 who use the internet have set up their own profile on a social networking site. For adults, the likelihood of setting up a profile is highest among16-24 year olds (54\%) and decreases with age.

\section{Figure 5: Social networks allow for global interaction}

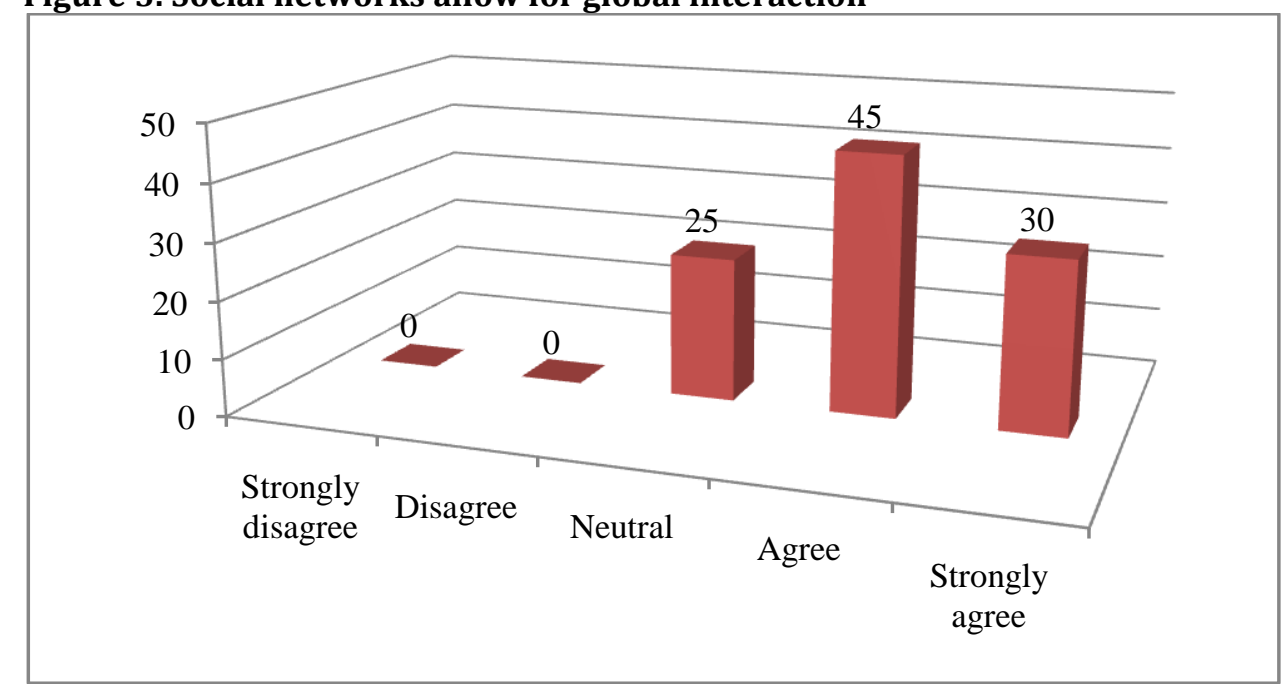

As indicated by Figure 5, 30\% of the respondents strongly agreed that social networks allow for global interaction, $45 \%$ agreed whilst $25 \%$ were neutral. None of the respondents disagreed that social networks allow for global interaction.

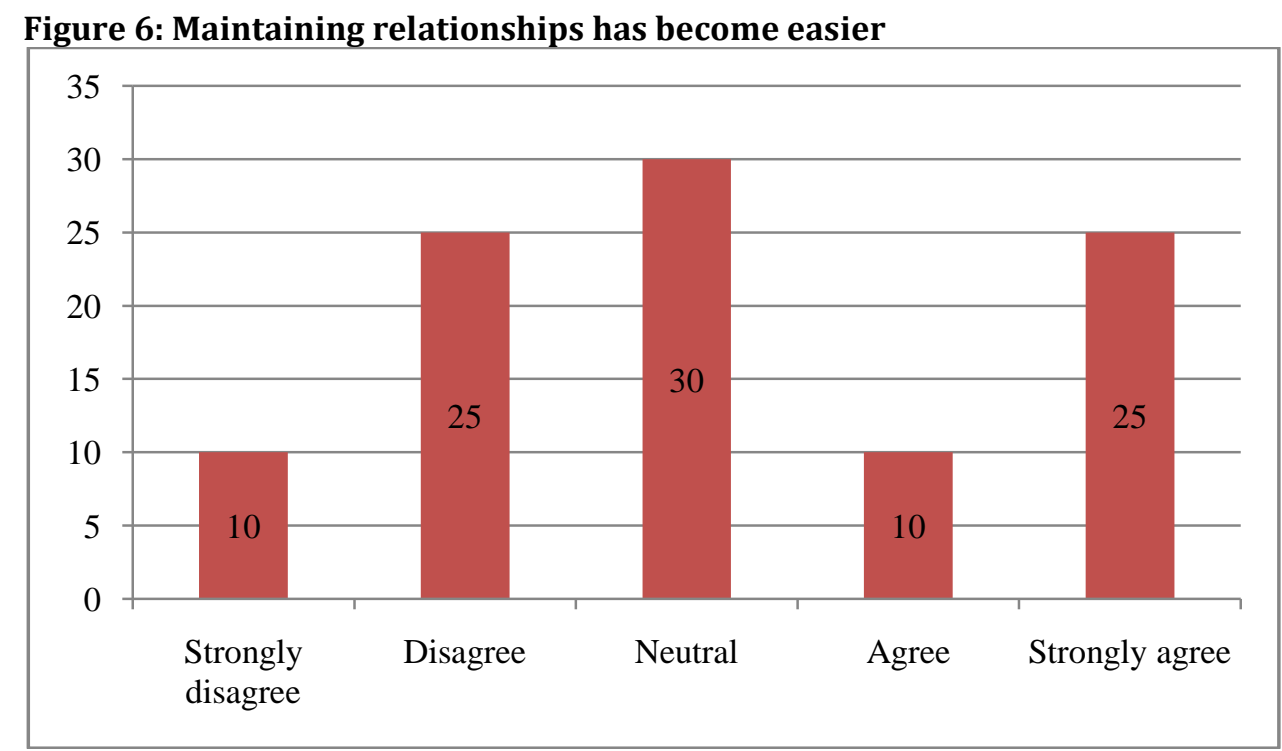

When posed the question of whether maintaining relationships has become easier with social networking, $25 \%$ of the respondents strongly agreed, $10 \%$ agreed, $30 \%$ were neutral, $25 \%$ disagreed and $10 \%$ strongly disagreed as indicated by Figure 6 . The Ofcom (2008) reported that about two-thirds of its respondents were talking to friends and family, $47 \%$ looked for old friends and $35 \%$ talked to people who were friends of friends. In comparison, $17 \%$ talked to people they didn't know. However, those who reported talking to people they didn't know were significantly more likely to be $16-24$ (22\%) year olds than 25-34 (7\%) year olds. 
Figure 7: Social networks impact on students' lives

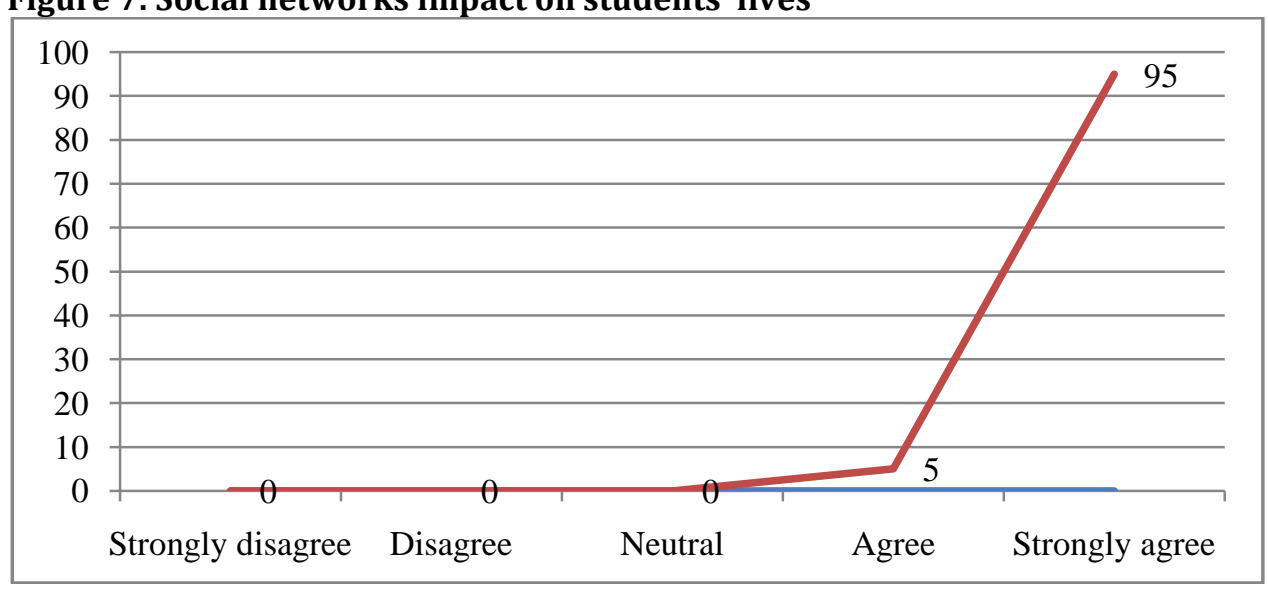

The responses when asked whether social networks affect students' lives were as follows: $95 \%$ strongly agreed and 5\% agreed as indicated by Figure 7. No respondents were neutral or disagreed, leading to the conclusion that there was very strong agreement that social networks affect students' lives.

Figure 8: How social networking is used by students?

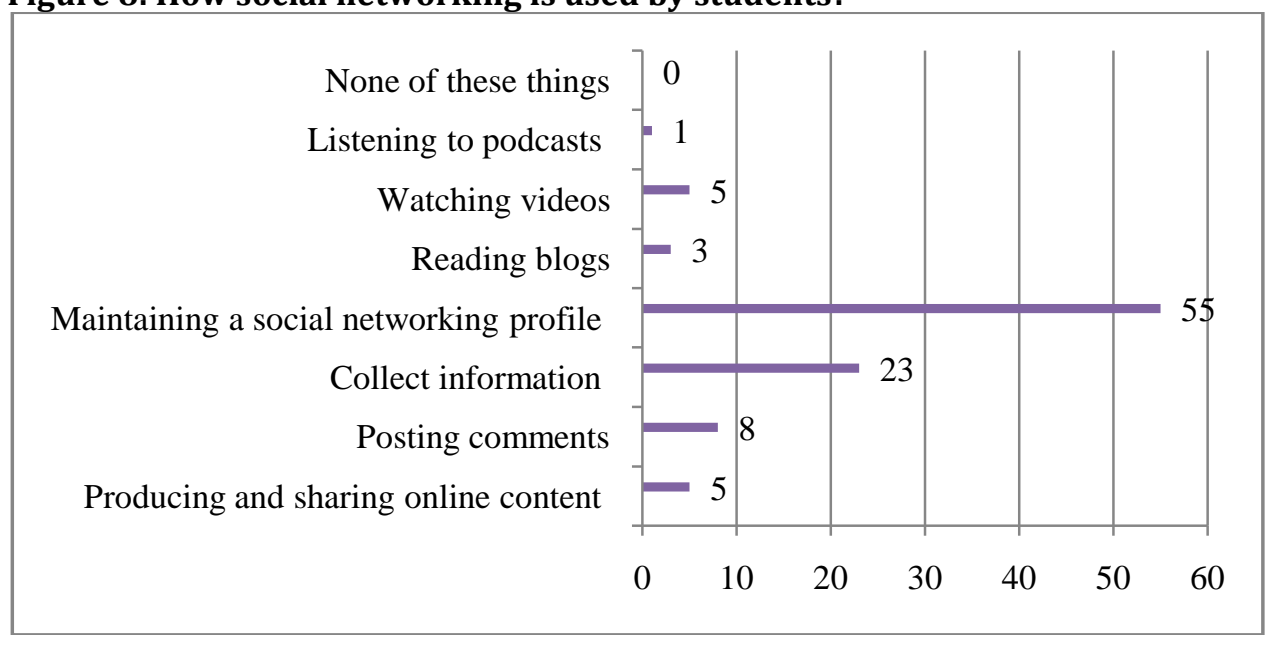

Figure 8 indicates that $55 \%$ of the respondents used social networking to maintain a profile, $23 \%$ to collect information, $8 \%$ for posting comments, $5 \%$ each for producing and sharing online content and watching videos, $3 \%$ for reading blogs, $1 \%$ listen to podcasts. A 2009 study found that $24 \%$ of social media users functioned as creators, $37 \%$ as critics, $21 \%$ as collectors, $51 \%$ as joiners and $73 \%$ as spectators. While participation in each of these categories trended upwards, inactives had decreased from $44 \%$ in 2007 to only $18 \%$ in 2009 . Research also shows that more social networking 'rookies' are classified as joiners. A new category, 'conversationalists' or people who post status updates on SNSs such as Twitter has emerged. Conversationalists represent $31 \%$ of users. This type of classification gives marketers a general idea of who is using social media and how to engage them (Lamb, Hair and McDaniel, 2013). However, using social networking sites is not exclusively about communication. Respondents also reported looking at others' sites without leaving messages (40\%) and listening to music/finding out about bands (29\%). 16-24 year olds (42\%) and males (34\%) were more likely than others $(29 \%$ UK average) to say they used social networking sites to listen to music.

\section{Conclusion}

This paper examined whether social networks affect the lifestyles and behaviour of higher education students and analysed the extent to which these social networks influence the lifestyles and behaviour of higher education students. The results indicate that the majority of the respondents preferred Facebook as their social network of choice. More than half of the respondents indicated that they access their preferred social network five times or more per day. None of the respondents disagreed that social networks allow for global interaction. There was very strong agreement that social networks affect 
students' lives. The majority of the respondents used social networking to maintain a profile and secondly to collect information.

\section{References}

Albarran, A. B. (2013). Management of Electronic and Digital Media (5 $5^{\text {th }}$ Ed), Mason: Cengage Learning.

DuPlessis, F., van-Heerden, N. \& Cook, G. (2010). Integrated marketing communication(3 ${ }^{\text {rd }}$ Ed), Pretoria: Van Schaik Publishers.

Giannini-Jr, G. T. (2010). Marketing Public Relations: A Marketer's Approach to Public Relations and Social Media. Boston: Pearson.

Lamb, C. W., Hair-Jr, J. F. \& McDaniel, C. (2013). MKTG6. Mason: Cengage Learning.

Ofcom (Office of Communications). (2008). Social Networking: A quantitative and qualitative report into attitudes, behaviours and use. Retrieved 24 April 2013 http://stakeholders.ofcom.org.uk/market-data-research/

Schmidt, S. M. P. \& Ralph, D. L. (2011). Social Media: More Available Marketing Tools. The Business Review, $18(2), 37-43$.

Sekaran, U. (2003). Research Methods for Business: A Skill-Building Approach(4th Ed),NY: John Wiley.

Shimp, T. A. (2010). Integrated Marketing Communication in Advertising and Promotion. Sydney: Cengage Learning.

Strauss, J. \& Frost, R. (2012). E-Marketing (6 ${ }^{\text {th }}$ Ed), Boston: Pearson. 